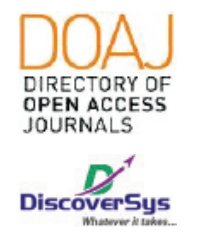

Published by DiscoverSys

'Departemen IImu Kesehatan Anak, Rumah Sakit Umum Daerah (RSUD) Wangaya, Denpasar, Bali, Indonesia

\section{Faktor - faktor yang berhubungan dengan kejadian anemia pada anak usia 6-59 bulan di RSUD Wangaya, Denpasar, Bali, Indonesia tahun 2019}

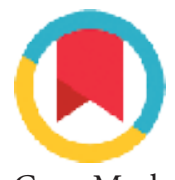

CrossMark

\author{
Elien Yuwono, ${ }^{1 *}$ I Wayan Bikin Suryawan, ${ }^{1}$ Anak Agung Made Sucipta ${ }^{1}$
}

\section{ABSTRACT}

Background: Anemia is one of the four micronutrient problems in Indonesia. Based on Global Prevalence on Anemia, the Southeast Asian region is one of the areas with the highest prevalence of anemic populations, more than $53.8 \%$ of children aged 6-59 months were classified as mild anemia, and $3.6 \%$ of them are severe anemia. In the first 1000 day birth gold period, anemia was associated with delays and developmental disorders, both motor and intellectual, which may be irreversible. This study aims to analyze the risk factors for the incidence of anemia to optimize child development.

Objective: To analyze the relations of the risk of age under two years old, low birth weight, underweight, short stunting, and not exclusive breastfeeding, to the incidence of anemia in children aged 6-59 months in Kaswari Room, Wangaya General Hospital, Denpasar in 2019.

Methods: Observational analytic epidemiology design with casecontrol study. The research subjects were determined by consecutive sampling method and fulfilled the inclusion criteria with a comparison of case and control groups, namely 1: 1. Data were analyzed bivariate by chi-square statistical test and Odds Ratio (OR) at the significance limit of $a=5 \%$, and multivariate analysis was performed with logistic regression test. Data was processed using the Statistical Package for Social Science (SPSS) version 23 for Windows program.

Results: The research subjects were 62 samples, consisting of 31 anemia samples, and 31 samples had no anemia. The results showed that there was no significant relationship between the risk of low birth weight and the incidence of anemia $(95 \% \mathrm{Cl}=0.80-22.29 ; \mathrm{p}$ : 0.073$)$, the risk of malnutrition with the incidence of anemia $(95 \% \mathrm{Cl}=0.81$ $63.85 ; \mathrm{p:} 0.052)$, and the risk of not exclusive breastfeeding with the incidence of anemia $(95 \% \mathrm{Cl}=0.21-1.63 ; \mathrm{p}$ : 0.440$)$. However, there was a significant relationship between the risk of age $<2$ years with the incidence of anemia $(0 \mathrm{R} 3.870 ; 95 \% \mathrm{Cl}=1.34-11.17 ; \mathrm{p}: 0.022)$ and the risk of short stature with the incidence of anemia (OR 7.686; $95 \%$ $\mathrm{Cl}=1,92-30.70 ; \mathrm{p:}$ 0.002). Logistic regression test results obtained significant results in short stature variables (sig 0.020; 0R 5.379).

Conclusion: age $<2$ years and short stature (stunting) have a significant relationship with the incidence of anemia in children aged 6-59 months in Kaswari Room, Wangaya Hospital, Denpasar in 2019.

Keywords: anemia, risk factors, underweight, stunting, exclusive breastfeeding

Cite this Article:Yuwono, E., Suryawan, I.W.B., Sucipta, A.A.M. 2020. Faktor - faktor yang berhubungan dengan kejadian anemia pada anak usia 6-59 bulan di RSUD Wangaya, Denpasar, Bali, Indonesia tahun 2019. Intisari Sains Medis 11(1): 75-80. D0I: 10.15562/ism.v11i1.572

\title{
ABSTRAK
}

Latar belakang : Anemia merupakan salah satu dari empat masalah gizi mikro masyarakat Indonesia. Berdasarkan Global Prevalence on Anaemia, regio Asia Tenggara menjadi salah satu kawasan dengan prevalensi tertinggi populasi anemia, lebih dari $53,8 \%$ anak usia 6-59 bulan diklasifikasikan anemia ringan, serta 3,6\% di antaranya adalah anemia berat. ${ }^{1}$ Pada periode emas 1000 HPK, anemia berhubungan dengan keterlambatan dan gangguan perkembangan baik motorik maupun intelektual yang mungkin irreversible. ${ }^{2}$ Penelitian ini bertujuan untuk menganalisis faktor-faktor risiko kejadian anemia sebagai langkah mengoptimalkan tumbuh kembang anak.

Tujuan : Menganalisis hubungan risiko usia $<2$ tahun, berat badan lahir rendah, gizi kurang (underweight), perawakan pendek (stunting), dan tidak ASI eksklusif, terhadap kejadian anemia pada anak usia 6-59 bulan di Ruang Kaswari, RSUD Wangaya, Denpasar tahun 2019.

Metode : Rancangan epidemiologi analitik observasional dengan desain studi case control. Subyek penelitian ditentukan dengan metode consecutive sampling, serta memenuhi kriteria inklusi dengan perbandingan kelompok kasus dan kontrol yaitu 1:1. Data dianalisis bivariat dengan uji statistic chi-square dan Odds Ratio (OR) pada batas kemaknaan a 5\%, serta dilakukan analisis multivariat dengan uji regresi logistic. Data diproses menggunakan program Statistical Package for Social Science (SPSS) versi 23 for Windows.

Hasil : Subjek penelitian sejumlah 62 sampel, terdiri dari 31 sampel anemia dan 31 sampel tidak anemia. Hasil penelitian menunjukkan bahwa tidak didapatkan hubungan bermakna antara risiko berat badan lahir rendah dengan kejadian anemia $(95 \% \mathrm{Cl}=0,80-22,29$; p:0,073), risiko gizi kurang dengan kejadian anemia $(95 \% \mathrm{Cl}=0,81$ 63,85; p:0,052), serta risiko tidak ASI eksklusif dengan kejadian anemia $(95 \% \mathrm{Cl}=0,21-1,63 ; \mathrm{p}: 0,440)$. Namun didapatkan hubungan bermakna antara risiko usia $<2$ tahun dengan kejadian anemia (OR 3,870; $95 \% \mathrm{Cl}=1,34-11,17 ; \mathrm{p}: 0,022)$ dan risiko perawakan pendek dengan kejadian anemia (0R 7,686; $95 \% \mathrm{Cl}=1,92-30,70 ; \mathrm{p}: 0,002)$. Hasil uji regresi logistic, didapatkan hasil bermakna pada variabel perawakan pendek (sig 0,020; 0R 5,379).

Kesimpulan: usia $<2$ tahun dan perawakan pendek (stunting) memiliki hubungan bermakna dengan kejadian anemia pada anak usia 6-59 bulan di Ruang Kaswari, RSUD Wangaya, Denpasar tahun 2019.
Disetujui: 03-01-2020

Diterbitkan: 03-03-2020 
Kata kunci: anemia, faktor risiko, underweight, stunting, ASI eksklusif

Cite Pasal Ini: Yuwono, E., Suryawan, I.W.B., Sucipta, A.A.M. 2020. Faktor - faktor yang berhubungan dengan kejadian anemia pada anak usia 6-59 bulan di RSUD Wangaya, Denpasar, Bali, Indonesia tahun 2019. Intisari Sains Medis 11(1): 75-80. D0l: 10.15562/ism.v11i1.572

\section{PENDAHULUAN}

Anemia merupakan salah satu dari empat masalah gizi mikro masyarakat Indonesia. Berdasarkan Global Prevalence on Anaemia, Asia Tenggara merupakan salah satu kawasan dengan prevalensi anemia tertinggi, lebih dari 53,8\% anak usia 6-59 bulan didapatkan menderita anemia ringan, serta 3,6\% lainnya menderita anemia berat. ${ }^{1}$ Sedangkan di Indonesia, berdasarkan hasil Riset Kesehatan Dasar tahun 2013, prevalensi nasional anemia sebesar 11,9\% dan sebagian besar yang mengalami anemia adalah anak kelompok usia 1-5 tahun $(28,1 \%)$, diikuti kelompok usia 5-14 tahun $(18,1 \%)$ dan cenderung menurun pada kelompok remaja. ${ }^{2}$

Pada periode emas 1000 hari pertama kehidupan (1000 HPK), anemia berakibat terhadap kurangnya asupan oksigen ke otak. Anemia kronis berhubungan dengan keterlambatan dan gangguan perkembangan baik motorik maupun intelektual yang mungkin irreversible. ${ }^{3}$ Penelitian pada hewan coba mendapatkan bahwa hewan yang mengalami anemia akan mengalami penurunan aktivitas spontan. ${ }^{3}$ Selanjutnya, penelitian oleh Lubis (2008) di Indonesia, didapatkan bahwa tingkat kecerdasan (IQ) anak sekolah dasar yang menderita anemia lebih rendah dari rata-rata anak seusianya (rerata $=83,8) .{ }^{4}$ Begitupula dengan peneltian Peiyu Wang tahun 2015, anemia dikatakan dapat berdampak pada gangguan fungsi imunitas, penurunan performa kognitif dan perilaku, serta gangguan pertumbuhan, di mana didapatkan hubungan yang bermakna antara kondisi stunting ( TB/U Z <-2 Z Score) dengan kejadian anemia pada balita di Myanmar dengan OR 5,018 ( $\mathrm{p}=0,008){ }^{5}$

Berdasarkan penelitian-penelitian tersebut, diketahui bahwadampak anemia pada anak sangat bervariasi mulai dampak yang masih dapat ditangani (reversible) hingga dampak yang tidak dapat ditangani (irreversible). Oleh karena itu sangat penting untuk mengetahui faktor-faktor apa saja yang berpengaruh sehingga anak mengalami anemia. Beberapa faktor sepert usia, jenis kelamin, berat badan lahir, status gizi berdasarkan indikator berat badan dibanding usia $(\mathrm{BB} / \mathrm{U})$, tinggi badan dibanding usia (TB/U), dan pemberian ASI Eksklusif diduga berpengaruh terhadap kejadian anemia. ${ }^{3}$ Keseluruhan faktor ini tergolong faktor intrinsik dan beberapa penelitian menemukan bahwa anak usia $<2$ tahun, jenis kelamin laki-laki, memiliki kecepatan pertumbuhan yang tinggi oleh karena itu anak dengan karakteristik tersbut sangat mudah mengalami anemia., ${ }^{3,4}$ Sedangkan, anak dengan berat badan lahir rendah, BB/U dibawah rerata, $\mathrm{TB} / \mathrm{U}$ dibawah rerata, dan tidak diberikan asi eksklusif cenderung mempunyai cadangan besi yang rendah dan mengalami anemia.,

Selain karakteristik balita, faktor maternal dan sosiodemografi juga dapat menjadi fakor risiko anemia pada balita. ${ }^{3}$ Oleh karena pentingnya mengetahui faktor terjadinya anemia untuk mencegah penyakit yang irreversible dan karena kurangnya penelitian yang meneliti karakteristik-karakteristik tersebut terhadap kaitannya dengan anemia di Indonesia, khususnya di Provinsi Bali. Peneliti tertarik untuk melakukan penelitian yang bertujuan untuk menganalisis faktor-faktor risiko kejadian anemia sebagai langkah mengoptimalkan tumbuh kembang anak.

\section{METODE PENELITIAN}

\section{Rancangan Penelitian}

Penelitian ini menggunakan rancangan observasional analitik design case control dengan perbandingan kasus dan kontrol adalah 1:1. Kelompok kasus adalah semua anak dengan anemia dan kelompok kontrol adalah semua anak tanpa anemia. Berdasarkan rumus besar sampel, masing-masing jumlah kasus dan kontrol adalah sebanyak 31 sampel. ${ }^{6}$ Kriteria inklusi semua anak usia 6-59 bulan yang dirawat di Ruang Kaswari, RSUD Wangaya, Denpasar, pada bulan Mei hingga Juni tahun 2019 dengan data kuisioner penelitian lengkap serta penandatangan informed consent bagi orang tua masing-masing sampel. Kriteria eksklusi yaitu anak dengan kelainan kongenital (Congenital disorder), anak dengan anemia berat (kadar $\mathrm{Hb}$ $<7 \mathrm{gr} / \mathrm{dl}$ ), memiliki riwayat suplementasi besi/transfusi darah enam bulan terakhir, memiliki riwayat perdarahan akut spontan, gangguan elektrolit, atau data kuesioner penelitian tidak lengkap.

\section{Variabel Penelitian}

Dilakukan analisa faktor-faktor yang mempengaruhi kejadian anemia yaitu usia $<2$ tahun, berat badan lahir rendah, status gizi kurang (underweight), perawakan pendek (stunting) danpemberian ASI Eksklusif. Anemia didefinisikan sebagai kadar $\mathrm{Hb}<-2 \mathrm{SD}$ sesuai usia, usia 6 bulan - 2 tahun bila $\mathrm{Hb}<10.5 \mathrm{gr} / \mathrm{dl}$, usia 2 tahun - 5 tahun bila $\mathrm{Hb}$ $<11.5 \mathrm{gr} / \mathrm{dl}$. Definisi berat badan lahir rendah (BBLR) bila berat lahir kurang dari 2500 gr. Sedangkan status gizi kurang (underweight) adalah $\mathrm{BB} / \mathrm{U} \mathrm{Z}<-2 \mathrm{SD} \mathrm{Z}$ 
score dan perawakan pendek (stunting) adalah $\mathrm{TB} / \mathrm{U}$ $\mathrm{Z}<-2 \mathrm{SD} \mathrm{Z}$ score. Pemberian ASI dikatakan ekslusif apabila hanya diberikan asupan ASI sampai usia 6 bulan tanpa menambahkan atau mengganti dengan makanan/minuman lain.

\section{Analisis data}

Hasil penelitian yang berupa data numerik akan dilakukan uji normalitas Kolmogorov - smirnov terlebih dahulu sebelum dilakukan analisis deskriptif. Data berdistribusi normal $(\mathrm{p}>0,05)$ akan disajikan dengan rerata dan simpang baku (SB), sedangkan data berdistribusi tidak normal akan disajikan dengan median, nilai minimum-maksimum. ${ }^{6}$

Analisis bivariat dilakukan dengan uji Chi square dan Odds Ratio (OR.) Analisis multivariat dilakukan dengan uji regresi logistik dengan tingkat kemaknaan $\mathrm{p}<0,05 .{ }^{6}$ Data diproses menggunakan program Statistical Package for Social Science (SPSS) versi 23 for Windows.

\section{HASIL PENELITIAN}

Subjek penelitian berjumlah 62 sampel, terdiri dari 31 sampel anemia dan 31 sampel tidak anemia.

Tabel 1 Karakteristik Sampel Penelitian

\begin{tabular}{|c|c|c|c|}
\hline Karakteristik & $\begin{array}{c}\text { Anemia } \\
(n=31)\end{array}$ & $\begin{array}{c}\text { Tidak Anemia } \\
(\mathrm{n}=\mathbf{3 1})\end{array}$ & $\begin{array}{c}\text { Total } \\
(n=62)\end{array}$ \\
\hline \multicolumn{4}{|l|}{ Usia, n (\%) } \\
\hline 6 Bulan - 2 Tahun & $22(71)$ & $12(38,7)$ & $34(54,8)$ \\
\hline$>2$ Tahun & $9(29)$ & $19(61,3)$ & $28(45,2)$ \\
\hline \multicolumn{4}{|l|}{ Jenis Kelamin, n (\%) } \\
\hline Perempuan & $12(38,7)$ & $16(51,6)$ & $28(45,2)$ \\
\hline Laki-laki & $19(61,3)$ & $15(48,4)$ & $34(54,8)$ \\
\hline \multicolumn{4}{|l|}{ Metode Persalinan, n (\%) } \\
\hline SC & $7(22,6)$ & $13(41,9)$ & $20(32,3)$ \\
\hline Spontan & $24(77,4)$ & $18(58,1)$ & $42(67,7)$ \\
\hline \multicolumn{4}{|l|}{ Berat badan lahir, n (\%) } \\
\hline$<2500$ gr & $7(22,6)$ & $2(6,5)$ & $9(14,5)$ \\
\hline$\geq 2500 \mathrm{gr}$ & $24(77,4)$ & $29(93,5)$ & $53(85,5)$ \\
\hline \multicolumn{4}{|l|}{ Status Imunisasi, n (\%) } \\
\hline Lengkap & $30(96,8)$ & $31(100)$ & $61(98,4)$ \\
\hline Tidak Lengkap & $1(3,2)$ & $0(0)$ & $1(1,6)$ \\
\hline \multicolumn{4}{|l|}{ Status ASI Eksklusif, n (\%) } \\
\hline ASI Eksklusif & $15(48,4)$ & $11(35,5)$ & $26(41,9)$ \\
\hline Tidak ASI Eksklusif & $16(51,6)$ & $20(64,5)$ & $36(58,1)$ \\
\hline \multicolumn{4}{|l|}{ Status Gizi, n (\%) } \\
\hline \multicolumn{4}{|l|}{ Indikator $\mathrm{BB} / \mathrm{U}$} \\
\hline Gizi Buruk & $1(3,2)$ & $0(0)$ & $1(1,6)$ \\
\hline Gizi Kurang & $5(16,1)$ & $1(3,2)$ & $6(9,7)$ \\
\hline Gizi Baik & $25(80,6)$ & $30(96,8)$ & $55(88,7)$ \\
\hline \multicolumn{4}{|l|}{ Indikator $\mathrm{TB} / \mathrm{U}$} \\
\hline Sangat Pendek & $5(16,1)$ & $0(0)$ & $5(8,1)$ \\
\hline Pendek & $9(29)$ & $3(9,7)$ & $12(19,4)$ \\
\hline Normal & $17(54,8)$ & $28(90,3)$ & $45(72,5)$ \\
\hline \multicolumn{4}{|l|}{ Laboratorium } \\
\hline Kadar Hb (median, min-max) & $10,3(7-11,5)$ & $12,2(10,7-14,2)$ & \\
\hline $\mathrm{MCV}$ & $73,2(55,6-95,5)$ & $78,8(72,5-95,3)$ & \\
\hline $\mathrm{MCH}($ rerata, SB) & $23,5(3,4)$ & $26,3(1,8)$ & \\
\hline $\mathrm{MCHC}$ & $31,5(1,8)$ & $33,5(1,1)$ & \\
\hline
\end{tabular}


Tabel 2 Analisis Bivariat

\begin{tabular}{|c|c|c|c|c|c|}
\hline \multirow[b]{2}{*}{ Variabel Penelitian } & \multicolumn{2}{|c|}{ Status Anemia } & \multirow[b]{2}{*}{ OR } & \multirow{2}{*}{$\begin{array}{l}\text { Interval Kepercayaan } \\
\text { (IK) } 95 \%\end{array}$} & \multirow[b]{2}{*}{$\mathbf{P}$} \\
\hline & Anemia & Tidak Anemia & & & \\
\hline Usia $<2$ tahun & 22 & 12 & 3,870 & $1,34-11,17$ & 0,022 \\
\hline BBLR & 7 & 2 & 4,229 & $0,80-22,29$ & 0,073 \\
\hline Gizi Kurang & 6 & 1 & 7,200 & $0,81-63,85$ & 0,052 \\
\hline Perawakan Pendek & 14 & 3 & 7,686 & $1,92-30,70$ & $0,002^{*}$ \\
\hline
\end{tabular}

Tabel 3 Analisis Multivariat

\begin{tabular}{lccc}
\hline Variabel Penelitian & OR & Interval Kepercayaan (IK) 95\% & P \\
\hline Usia $<2$ tahun & 2,267 & $0,68-7,50$ & 0,18 \\
BBLR & 2,489 & $0,38-16,31$ & 0,34 \\
Gizi Kurang & 6,483 & $0,61-68,41$ & 0,12 \\
Perawakan Pendek & 5,699 & $1,30-24,79$ & $0,02^{*}$ \\
\hline
\end{tabular}

OR = Odds Ratio; IK = Interval kepercayaan; ${ }^{*} \mathrm{P}<0.05$ : berbeda bermakna secara statistik

Dari keseluruhan sampel didapatkan lebih banyak sampel berkelamin laki-laki $(54,8 \%)$ dibandingkan perempuan $(45,2 \%)$. Sedangkan, dari 31 sampel yang mengalami anemia, didominasi oleh kelompok usia 6 bulan-2 tahun (71\%). Selain itu, berdasarkan berat badan lahir, kasus anemia didapatkan dominan pada sampel yang memiliki berat $\geq 2500$ gr saat lahir $(77,4 \%)$. Dari status gizi, didapatkan bahwa sebanyak $80,6 \%$ sampel anemia memiliki status gizi baik berdasarkan indikator $\mathrm{BB} / \mathrm{U}$ sedangkan dari indikator TB/U didapatkan 54,8\% sampel anemia mempunyai tinggi badan normal sesuai usia (Tabel 1).

Hasil penelitian menunjukkan bahwa tidak didapatkan hubungan bermakna antara risiko berat badan lahir rendah dengan kejadian anemia (IK 95\% $=0,80-22,29 ; \mathrm{p}=0,073$ ), risiko gizi kurang (underweight) dengan kejadian anemia (IK 95\% = $0,81-63,85 ; \mathrm{p}=0,052)$, serta risiko tidak ASI eksklusif dengan kejadian anemia (IK 95\% $=0,21-1,63$; $\mathrm{p}=0,440$ ). Namun didapatkan hubungan bermakna antara risiko usia $<2$ tahun dengan kejadian anemia (OR 3,870; IK 95\% = 1,34 - 11,17; p=0,022) dan risiko perawakan pendek (stunting) dengan kejadian anemia adalah (OR 7,686; IK 95\% = 1,92 - 30,70; $\mathrm{p}=0,002)$ (Tabel 2). Hasil uji regresi logistic, didapatkan hasil bermakna hanya pada variabel perawakan pendek $(p=0,02 ; O R=5,379)$, sedangkan variabel usia, BBLR, dan status gizi kurang tidak bermakna terhadap kejadian anemia (Tabel 3).

\section{PEMBAHASAN}

Berdasarkan hasil penelitian, didapatkan hubungan bermakna antara usia $<2$ tahun dengan kejadian anemia (OR 3,87; IK 95\% = 1,34 - 11,17), dengan persentase tertinggi kejadian anemia terdapat pada kelompok usia 6 bulan -2 tahun (71\%). Hal ini sejalan dengan penelitian Cristie tahun 2016, di mana prevalensi anemia pada kelompok umur $<2$ tahun mencapai $76,17 \%$ dan berisiko terhadap kejadian anemia dengan (OR 1,88; IK 95\% CI = 1,15-3,09). ${ }^{7}$ Penelitian Marie pada tahun 2015 juga mendapatkan hasil yang serupa, dengan prevalensi kejadian anemia lebih tinggi pada kelompok umur $<2$ tahun $(62,7 \%)$ dengan nilai $\mathrm{p}$ yang bermak$\mathrm{na}(\mathrm{p}<0,01) .{ }^{8}$ Menurut penelitian Georgieff dkk (2013), kecenderungan terjadi anemia defisiensi besi anak tertinggi pada usia trimester ketiga janin sampai saat kelahiran, late infancy-early toddler yaitu usia 6 bulan sampai 3 tahun, serta saat masa pubertas. ${ }^{9}$ Kecenderungan tinggi akan terjadinya anemia dihubungkan dengan adanya peningkatan kebutuhan akan besi (iron demand) saat periode usia tersebut. ${ }^{9}$ Selain itu, perkembangan pesat maturasi hipokampus terjadi antara usia 3-18 bulan, di mana terjadi stimulasi hormon pertumbuhan dan puncak synaptogenesis, sehingga terdapat peningkatan aktivitas metabolik, penggunaan energi, dan uptake zat besi di otak. Pada usia inilah anak rentan mengalami anemia dan kemudian berdampak pada perkembangan intelektual anak. ${ }^{10}$

Berdasarkan jenis kelamin, sebagian besar sampel berjenis kelamin laki-laki diikuti dengan perempuan, namun tidak didapatkan perbedaan bermakna prevalensi anemia pada kelompok laki-laki dan perempuan yaitu $55,8 \%$ dan $42,8 \%$. Sebagian besar sampel lahir dengan metode persalinan spontan dan memiliki status imunisasi lengkap dengan perbedaan persentase antara kelompok kasus dan kontrol tidak terlalu bermakna. Hal ini sejalan dengan penelitian Claudia tahun 2013 yang menyatakan bahwa tidak ada hubungan bermakna antara metode persalinan dengan risiko kejadian anemia pada balita, dengan nilai $\mathrm{p}>0,05 .{ }^{11}$ 
Berdasarkan berat badan lahir, sebagian besar sampel lahir dengan berat badan $\geq 2500$ gr, meski tidak didapatkan hubungan yang signifikan antara variabel berat badan lahir rendah dengan kejadian anemia $(p=0,149)$, namun persentase anemia pada kelompok dengan berat badan lahir rendah cukup tinggi, mencapai $77,8 \%$. Hal ini sejalan dengan penelitian Claudia Ferri tahun 2013, didapatkan berat badan lahir rendah tidak berisiko terhadap kejadian anemia pada balita $(\mathrm{p}=0,161) \cdot{ }^{11}$ Namun tidak sejalan dengan penelitian Anjar Noviani pada tahun 2015, di mana anak dengan berat badan lahir rendah berisiko mengalami anemia dengan nilai OR 4,36 (IK 95\% = 2,74-6,94). ${ }^{3}$

Sedangkan berdasarkan status gizi, sebagian besar kelompok kasus dan kontrol memiliki gizi baik dan perawakan normal. Meski tidak didapatkan hubungan bermakna antara gizi kurang (underweight) dengan kejadian anemia $(\mathrm{p}=0,052)$, sampel dengan gizi kurang sebagian besar mengalami anemia dengan persentase mencapai $85,7 \%$. Hal ini sejalan dengan uji regresi logistik Peiyu Wang tahun 2015, didapatkan bahwa sampel gizi kurang(BB/U $\mathrm{Z}<-2$ $\mathrm{Z}$ Score) tidak berisiko terhadap kejadian anemia pada balita di Myanmar dengan $(\mathrm{p}=0,506) .{ }^{5}$ Berbeda dengan statys gizi kurang yang secara statistik tidak bermakna terhadap anemia, perawakan pendek memperoleh hubungan bermakna dengan $O R=$ $7,686(\mathrm{p}=0,002)$ serta pada regresi logistik didapat $\mathrm{OR}=5,37(\mathrm{p}=0,020)$. Sehingga perawakan pendek (stunting) menjadi salah satu faktor yang paling berpengaruh terhadap kejadian anemia pada penelitian ini. Hal serupa didapatkan pada penelitian Peiyu Wang tahun 2015, hasil regresi logistik yaitu stunting ( $\mathrm{TB} / \mathrm{U} \mathrm{Z}<-2 \mathrm{Z}$ Score) berisiko terhadap kejadian anemia pada balita di Myanmar dengan $\mathrm{OR}=5,018(\mathrm{p}=0,008) .{ }^{5}$ Rima Rafiq tahun 2011 dan Yumei Zhang tahun 2012 juga memperoleh hasil yang signifikan dengan berturut-turut $p=0,003$ dan $\mathrm{p}=0,017$ (OR 1,66). ${ }^{12,13}$ Hal ini dapat disebabkan karena wasting dan underweight merupakan dampak dari kekurangan nutrisi jangka waktu yang lebih pendek, sehingga hanya mencerminkan besarnya masalah gizi pada saat ini. ${ }^{14}$ Sedangkan stunting menggambarkan terhambatnya pertumbuhan oleh karena malnutrisi jangka panjang, di mana seperti yang kita ketahui, sebagian besar anemia pada balita disebakan oleh anemia defisiensi besi (malnutrisi kronis akan kebutuhan zat besi). ${ }^{15}$ Anemia dapat berdampak pada pertumbuhan linear seorang anak, salah satunya melalui mekanisme terjadinya hypoxia jaringan yang kemudian menurunkan sekresi Growth Hormone dan insulin-like growth factor-I / IGF-I (GH-IGF-I axis mechanism). ${ }^{10}$

Prevalensi sampel tidak memperoleh ASI eksklusif mencapai $58,1 \%$ dengan kejadian anemia tidak berbeda signifikan antara kelompok ASI eksklusif dan tidak mendapat ASI eksklusif, serta tidak didapatkan hubungan bermakna secara statistik $(\mathrm{p}=0,440)$. Hal ini sejalan dengan penelitian Rima Rafiq tahun 2015, di mana prevalensi ASI eksklusif hanya mencapai $24,4 \%$ dan tidak terkait dengan kejadian anemia $(\mathrm{p}=0,312) \cdot{ }^{12}$ Rini Sekartini tahun 2016 juga memperoleh hasil tidak bermakna dengan $p=0,778$ dan $p>0,05 .{ }^{16}$

Penelitian ini memiliki beberapa kelemahan, antara lain subjek penelitian kurang variatif karena hanya mengambil dari satu rumah sakit sehingga tidak bisa digeneralisasikan serta waktu pengumpulan sampel yang cukup singkat. Kemudian hasil pemeriksaan kadar hemoglobin dapat dipengaruhi oleh berbagai faktor seperti kelainan elektrolit, gangguan metabolik/ dehidrasi, atau penyakit inflamasi/ infeksi kronis yang belum digali lebih dalam, sehingga memungkinan dapat mempengaruhi hasil pemeriksaan. Untuk itu diperlukan suatu penelitian lebih lanjut guna mengetahui faktor-faktor terkait kejadian anemia pada anak.

\section{KESIMPULAN}

Penelitian ini menunjukkan bahwa terdapat beberapa faktor yang berperan terhadap kejadian anemia pada anak. Faktor-faktor yang mempunyai hubungan signifikan dengan kejadian anemia pada anak usia 6-59 bulan di Ruang Kaswari, RSUD Wangaya, Denpasar adalah usia $<2$ tahun dan perawakan pendek (stunting).

\section{KONFLIK KEPENTINGAN}

Tidak terdapat konflik kepentingan dalam penelitian ini.

\section{ETIKA PENELITIAN}

Penelitian ini telah disetujui oleh Komisi Etik Penelitian Rumah Sakit Umum Daerah Wangaya, Denpasar.

\section{PENDANAAN}

Penelitian ini tidak mendapatkan pendanaan dari pihak manapun.

\section{KONTRIBUSI PENULIS}

Seluruh penulis memiliki kontribusi yang sama dalam penelitian ini, mulai dari perencanaan konsep, pengambilan data, analisis data, hingga interpretasi data. 


\section{DAFTAR PUSTAKA}

1. de Benoist $\mathrm{B}$ et al., eds. Worldwide prevalence of anaemia 1993-2005. WHO Global Database on Anaemia Geneva, World Health Organization, 2008.

2. Riset Kesehatan Dasar. Badan Penelitian dan Pengembangan Kesehatan. Kementerian Kesehatan RI. 2013.

3. Anjar N. Faktor-faktor yang berhubungan dengan kejadian anemia pada balita di Indonesia. Jurnal Kesehatan Masyarakat UIN Syarif Hidayatullah Jakarta. 2015:100-6.

4. Lubis B, Saragih RAC, Gunadi D, Rosdiana N, Andriani E. Perbedaan Respon Hematologi dan Perkembangan Kognitif pada Anak Anemia Defisiensi Besi Usia Sekolah Dasar yang Mendapat Terapi Besi Satu Kali dan Tiga Kali Sehari. Sari Pediatri. 2008; 10(3): 184-9.

5. Peiyu W, Yumei Z, Zhao A, Gao H, Kai Y, Win N, et al. Potential Contribution of Iron Deficiency and Multiple Factors to Anemia among 6- to 72-Month-Old Children in the Kokang Area of Myanmar. Am J Trop Med Hyg. 2015;93(4): 836-840.

6. Sastroasmoro, Sudigdo., Djajadiman Gatot, Nartono Kadri, dan Purnamawati S. Pudjiarto. Dasar-dasar Metodologi Penelitian Klinis. Jakarta : Sagung Seto. 2011:55

7. Christie R, Cesar A, Monica M, Bruno H. Prevalence and Risk Factors of Anemia in Children. Jornal de Pediatria. 2016; 92(4):353-360

8. Maria M, Mananga J, Tetanye E. Risk factors of anemia among young children in rural Cameroon. Int.J.Curr. Microbiol.App.Sci. 2015;4(3):925-935

9. Georgieff MK. The Specific Role of Iron in Early Brain Development. Biochemical Society Transaction. 2008;36(6):1267-71
10. Soliman A, Sanctis V, Yassin M, Ashraf A. Growth and growth hormone - Insulin Like Growth Factor I (GH-IGF-I) axis in chronic anemias. Acta Biomed 2017;88(1):101-111

11. Claudia F, Procianoy R, Silveira T. Prevalence and Risk Factors for Iron-Deficiency Anemia in Very-Low-BirthWeight Preterm Infants at 1 Year of Corrected Age. Journal of Tropical Pediatrics. 2014; 60(1):53-60.

12. Rima R, Soo K, Abed Y, Muda W. Anemia among children aged 2-5 years in the Gaza Strip- Palestinian. BMC Public Health. 2015;15:319

13. Yumei Z, Ying P, Peiyu W, Zhao A. Prevalence of Anemia and Its Risk Factors Among Children 6-36 Months Old in Burma. Am J Trop Med Hyg. 2012;87(2):306-311.

14. Situasi Gizi di Indonesia. Infodatin: Pusat Data dan Informasi Kementrian Kesehatan RI. 2016.

15. Halterman JS, Kaczorowski JM, Aligne A, Auinger P, Szilagyi PG. Iron Deficiency and Cognitive Achievement Among School-Aged Children and Adolescents in the United States. Pediatrics. 2001;107(6):1381-86

16. Sekartini R, Oedjadmiko, Wawolumaya C, Yuniar I, Dewi R, Nycane, et al. Prevalensi Anemia Defisiensi Besi pada Bayi Usia 4 - 12 Bulan di Kecamatan Matraman dan Sekitarnya, Jakarta Timur. Sari Pediatri. 2005;7(1):2-8

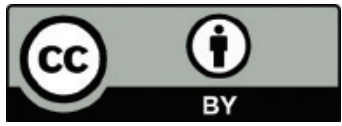

This work is licensed under a Creative Commons Attribution 